\title{
OPEN Novel wideband circularly polarized DRA with squint-free radiation characteristics
}

\begin{abstract}
Mohammad Abedian ${ }^{1}$, Mohsen Khalily ${ }^{1}$, Vikrant Singh ${ }^{1}$, Pei Xiao ${ }^{1}$, Rahim Tafazolli $^{1}$ \& Ahmed A. Kishk ${ }^{2}$

A new single-fed circularly polarized dielectric resonator antenna (CP-DRA) without beam squint is presented. The DRA comprises an S-shaped dielectric resonator (SDR) with a metalized edge and two rectangular dielectric resonators (RDRs) blocks. Horizontal extension section is applied as an extension of the SDR, and a vertical-section is placed in parallel to the metallic edge. A vertical coaxial probe is used to excite the SDR and the vertical RDR blocks through an S-shaped metal element and a small rectangular metal strip. The two added RDRs that form an L-shaped DR improve the radiation characteristics and compensate for the beam squint errors. A wideband CP performance is achieved due to the excitation of several orthogonal modes such as $T E_{\delta 11}^{x}, T E_{1 \delta 1}^{y}, T E_{121}^{z}, T E_{112}^{y}, T E_{131}^{x}$, and $T E_{311}^{y}$. The experimental results demonstrate an impedance bandwidth of approximately $66.8 \%$ (3.71-7.45 $\mathrm{GHz}$ ) and a 3-dB axial-ratio (AR) bandwidth of about $54.8 \%(3.72-6.53 \mathrm{GHz})$ with a stable broadside beam achieving a measured peak gain of about $4.64 \mathrm{dBic}$. Furthermore, a $100 \%$ correction in beam squint value from $\theta=41^{\circ}$ to $\theta=0^{\circ}$ with respect to the antenna boresight is achieved.
\end{abstract}

Dielectric resonator antennas (DRAs) have been widely studied due to their attractive features such as high radiation efficiency, low loss, no surface wave, various excitation mechanisms, light-weight, geometrical flexibility, and compact antenna size ${ }^{1-3}$. The $3 \mathrm{D}$ structure of DRAs provides a higher degree of flexibility over microstrip antennas that have been widely used in various systems $s^{4,5}$ but suffer from limited bandwidth and low radiation efficiency caused by the conduction losses ${ }^{6}$. Among the three main DRA shapes, rectangular DRA (RDRA) offers an added advantage of higher design flexibility as its three-dimensional structure can have different aspect ratios ${ }^{7}$.

In addition, the amalgamation of various DRA shapes and coupling schemes provides the flexibility to obtain the desired linear or circular polarization (CP). Linear polarization (LP) is sensitive to multipath reception and misalignment between transmitting and receiving antennas. In contrast, $\mathrm{CP}$ waves, which are usually excited by two orthogonal linearly polarized waves of equal amplitude and 90-degree phase difference, have received much attention because they offer more flexibility for the transmitter and receiver orientations along with the capability of mitigating polarization mismatch and suppressing multipath interference ${ }^{8-11}$. Recently, different shapes of the DR and various feeding mechanisms have been introduced to achieve wideband DRAs, operating in $\mathrm{CP}$, as a pathway to fulfill spectrum requirements by taking the advantages of better mobility and less multipath effects ${ }^{12-25}$. Two orthogonal modes must be excited with a quadratic phase difference to design circularly polarized DRA, which can be realized by single or multiple feed mechanisms. The single feed mechanism has a relatively simple structure but limited CP bandwidth. Moreover, the antenna's radiation performance can be degraded due to the asymmetry of the excitation. On the other hand, having a multiple feed network provides a wider CP bandwidth but results in a large and complex feeding structure. In the literature, several single-point feed DRAs have been introduced to enhance the CP bandwidth ${ }^{15-25}$. For instance, in ${ }^{17}$, a wideband CP quadruplestrip-fed cylindrical DRA with a CP bandwidth of $25.9 \%$ using a pair of $90^{\circ}$ hybrid couplers has been presented. A trapezoidal DRA excited by an inclined slot has been proposed in ${ }^{18}$, which offers a CP bandwidth of $21.5 \%$. In $^{19}$, a DRA with diagonal slits has been reported, which shows $43 \%$ AR bandwidth with an overlapped matching bandwidth of about $36 \%$. Zou et al. ${ }^{20}$ have introduced a RDRA excited by a spiral strip, achieving a CP bandwidth of $25.5 \%$. In parallel, by exciting a RDRA through a unique conformal $\mathrm{H}$-shaped metal strip, a wideband CP DRA with a CP bandwidth of $20 \%$ has been achieved ${ }^{21}$. Moreover, Yang et al. ${ }^{22}$ proposed a square DRA excited by a microstrip coupled cross-slot with four vertical metal plates around the DRA, achieving a CP bandwidth of $46.9 \%$ with an average gain of $4.69 \mathrm{dBic}$ within the desired operating band. A simple shaped RDRA with $20.8 \%$

${ }^{1}$ Institute for Communication Systems (ICS), Home of the 5G \& 6G Innovation Centres, University of Surrey, Guildford GU2 7XH, UK. ${ }^{2}$ Department of Electrical and Computer Engineering, Concordia University, Montreal QC H3G 2W1, Canada. ${ }^{\bowtie}$ email: m.abediankasgari@surrey.ac.uk 


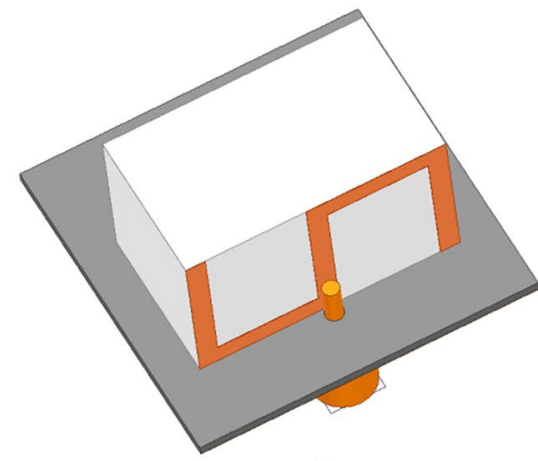

(a)

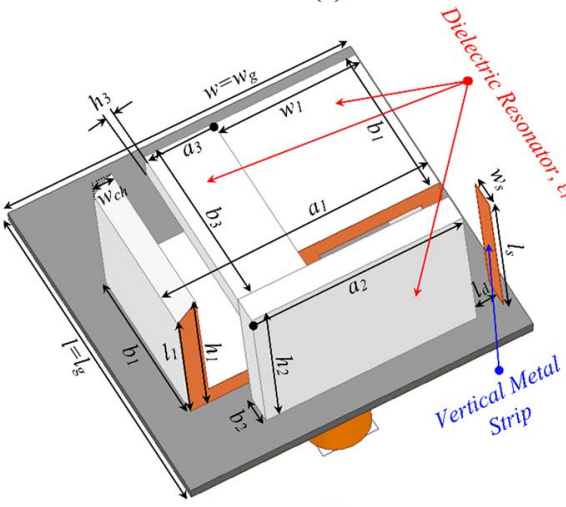

(d)

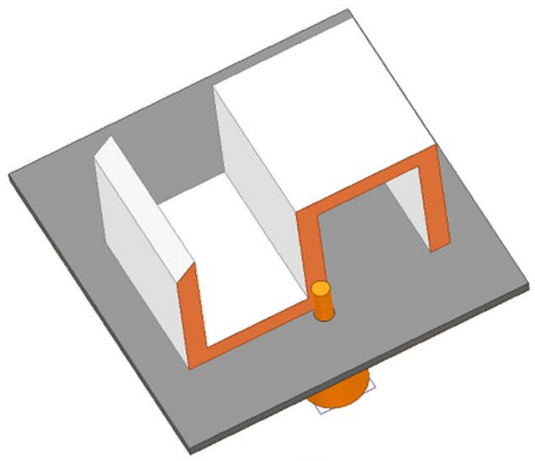

(b)

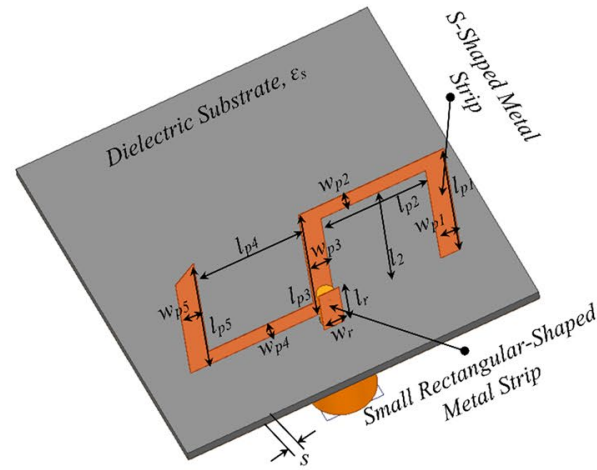

(e)

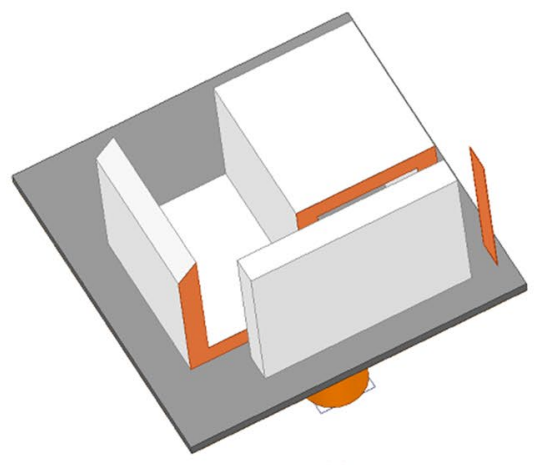

(c)

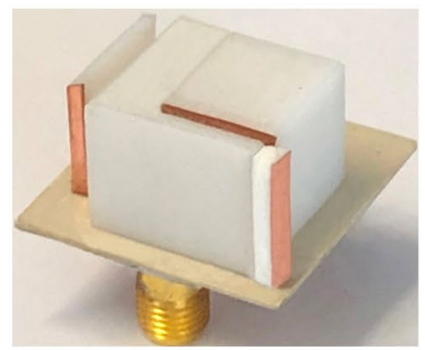

(f)

Figure 1. Evolution of the proposed CP DRA: (a) RDRA, (b) SDRA (Antenna I), (c) SDRA with the first added RDR and vertical metal strip (Antenna II), (d) SDRA with the first and the second added RDRs (Antenna III); Geometry of the proposed CP DRA, (e) feeding mechanism, and (f) the prototype of proposed DRA. $\left(l=l_{g}=26, w=w_{g}=26, l_{p 1}=l_{p 3}=l_{p 5}=12, l_{p 2}=l_{p 4}=7.75, w_{p 1}=w_{p 3}=w_{p 5}=1.5, w_{p 2}=w_{p 4}=2\right.$, $l_{r}=4, w_{r}=2, l_{s}=12, w_{s}=2, l_{d}=2, w_{c h}=1.5, l_{1}=10.5, l_{2}=10, w_{1}=10.75, a_{1}=20, b_{1}=12, h_{1}=12$, $a_{2}=16, b_{2}=2, h_{2}=12, a_{3}=5.25, b_{3}=13.345, h_{3}=2, \varepsilon_{r}=10, \varepsilon_{s}=3,=0.75$. Unit: $\left.\mathrm{mm}\right)$.

AR bandwidth and high radiation efficiency of more than $97 \%$ has been presented $\mathrm{in}^{23}$. A DRA containing rectangular and two half-split cylindrical DRs excited by a stair-shaped slot has been proposed in ${ }^{24}$ which offers $41.01 \%$ AR bandwidth but low gain. A hybrid antenna with a cylindrical DR and dual vertical microstrip lines arranged perpendicularly for obtaining wideband CP bandwidth of $24.6 \%$ has been reported in ${ }^{25}$. However, it is observed that the radiation bandwidth is narrower than the matching bandwidth as the radiation characteristics changes within the desired bandwidth.

On the other hand, for a CP antenna, the antenna beam steering performance can be adversely affected by the beam squint phenomenon and reducing antenna broadside gain. Beam squint is caused by exciting higherorder modes in the presence of the desired mode due to the asymmetry of the excitation and the geometry. Such squint is undesirable for communication as the co-component's peak amplitude is not in the broadside direction. This behavior introduces frequency selectivity to the wideband signal, resulting in the CP antenna's poor performance and compromised system efficiency. Therefore, it poses a significant limitation on its many practical applications, such as satellite and polarimetry ${ }^{26}$. One of the common techniques to excite orthogonal modes is to design an asymmetric resonator, but it may shift the main beam towards different angles rather than boresight. Furthermore, to widen the $\mathrm{CP}$, the position of feeding structure with respect to the resonator plays an important role and can cause the main beam's deviation from boresight. For example, the CP-DRAs in ${ }^{19,21,23,27-29}$ suffered from a large squint angle, which is more than $20^{\circ}$ due to the excited orthogonal modes' asymmetry in magnitude and phase between them. This article has proposed a new technique to remove the beam squint effect and widen the CP bandwidth with radiation characteristic enhancement. The design procedure and the measured and simulated results are discussed in the following sections.

\section{Antenna configuration and physical working mechanism}

The evolution and schematic of the proposed wideband CP-DRA is demonstrated in Fig. 1. Figure 1a represents the proposed DRA's initial design, where the CP bandwidth is limited to $4 \%$. Hence, the RDR is modified to enhance the CP bandwidth by introducing two equal hollow blocks in RDR with the key parameters $l_{p 2}=l_{p 4}$ and $l_{2}$ to form an SDR (see Fig. $1 \mathrm{~b}$ ) to reduce DR's Q-factor and enhance impedance matching. Figure $1 \mathrm{~b}-\mathrm{d}$ illustrate three different geometries of the DRA denoted as Antenna I, Antenna II, and Antenna III, respectively. Fig. 1d depicts the final design of proposed DRA, indicating the design parameters, while Fig. 1e presents the parameters associated with the feeding mechanism. To achieve wideband CP, an SDR with dimensions $a_{1} \times b_{1}$ $\times h_{1}$ excited by a coaxial probe through an S-shaped metal strip $l_{p} \times w_{p}$ (denoted as Antenna I, see Fig. 1b). The 


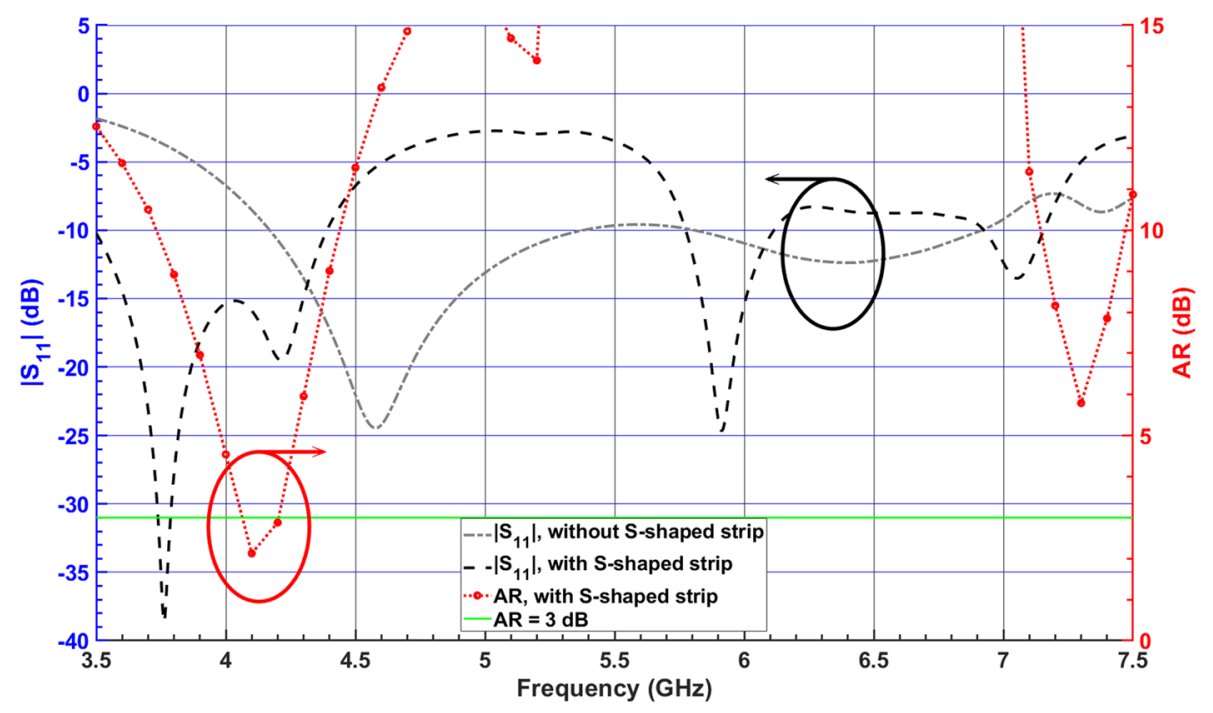

Figure 2. Simulated $\left|S_{11}\right|$ and AR of the RDRA with and without an S-shaped metal strip.

proposed DRA is supported by a grounded 26 ( $x$-axis) $m m \times 26$ (y-axis) $m m$ Rogers RO3003 substrate with a permittivity of $\varepsilon_{s}=3$ and a thickness of $s=0.75 \mathrm{~mm}$. Secondly, a RDR with dimensions of $a_{2} \times b_{2} \times h_{2}$ is placed close to the SDR, excited by a small rectangular-shaped metal, $l_{r} \times w_{r}$, attached to the coaxial probe. In addition, a vertical metal strip with dimensions of $l_{s} \times w_{s}$ is placed on one side of the new resonator at a distance of $l_{d}$, resulting in a wider antenna bandwidth (denoted as Antenna II, see Fig. 1c). Finally, another RDR of volume $a_{3}$ $\times b_{3} \times h_{3}$ is attached to the aforementioned DRs to improve the radiation characteristics (denoted as Antenna III, see Fig. 1d). All the DRs are made of ECCOSTOCK HiK dielectric material with relative permittivity $\varepsilon_{r}=$ 10 and loss tangent $\tan \delta=0.002$.

In this work, CST Microwave Studio 2019 is used to analyze and optimize the proposed antenna. From a topological point of view, this work's main contribution is exciting a single-fed CP antenna by applying an S-shaped parasitic strip attached to the DR block and, at the same time, compensating the beam squint error. It is worth noting that for further CP bandwidth improvement, two equal hollow blocks are introduced in the RDR. In parallel, two RDR blocks are placed to overcome the beam squint issue. This section describes the design process of the proposed DRA and physical mechanisms.

Wideband CP-DRA design. As illustrated in Fig. 1a, to couple the energy to the RDRA and excite multiple resonances in close vicinity, an S-shaped strip connected to the coaxial probe is attached to the RDRA while the initial dimensions of the RDRA are calculated using the dielectric waveguide model (DWM) equations ${ }^{2}$. Here, to generate CP fields, two orthogonal $T E^{x}$ and $T E^{y}$ modes with equal amplitude and $90^{\circ}$ phase difference are excited by using an S-shaped metal strip to indicate right-hand CP (RHCP) and left-hand CP (LHCP) waves components as follows ${ }^{8}$ :

$$
\begin{aligned}
& E_{R H C P}=\frac{1}{\sqrt{2}}\left(E_{x}+j E_{y}\right), \\
& E_{L H C P}=\frac{1}{\sqrt{2}}\left(E_{x}-j E_{y}\right) .
\end{aligned}
$$

According to image theory, the S-shaped strip current produces two distinct modes, common and differential, which correspond to exciting the $T E^{x}$ and $T E^{y}$ modes, respectively. The corresponding field components of each mode $\left(T E^{x}\right.$ and $\left.T E^{y}\right)$ are equal and can be expressed as follows ${ }^{7}$ :

$$
T E^{x}\left(E_{y}\right)=T E^{y}\left(E_{x}\right)=-A K_{z} \cos \left(K_{x} x\right) \cos \left(K_{y} y\right) \sin \left(K_{z} z\right) .
$$

Figure 2 shows the simulated $\left|S_{11}\right|$ and AR of the RDRA with and without an S-shaped parasitic element. It can be clearly observed that the S-shaped strip provides wider impedance bandwidth with an overlapping broadside AR bandwidth around $4.1 \mathrm{GHz}$. In order to obtain a wider CP bandwidth, the RDRA is modified to form an SDRA. Figure 3 shows the AR graph versus different values of $l_{p 2}=l_{p 4}$, at the resonance frequency of the corresponding first and second orthogonal mode pairs. It can be seen that as the length of $l_{p 2}=l_{p 4}$ increases, 3 -dB AR bandwidth improves for the first and second orthogonal modes.

The SDRA provides a wider 3-dB AR bandwidth, as shown in Fig. 4. However, the corresponding impedance bandwidth shows a degradation and does not satisfy the $-10-\mathrm{dB}\left|S_{11}\right|$ around $6 \mathrm{GHz}$. To improve the impedance matching, a corner of the SDRA is chamfered with $45^{\circ}$, called Antenna I, as shown in Fig. $1 \mathrm{~b}$. The simulated E-field distributions at $4.6 \mathrm{GHz}$ and $6.5 \mathrm{GHz}$ are shown in Fig. 5 for Antenna I. The figure indicates 


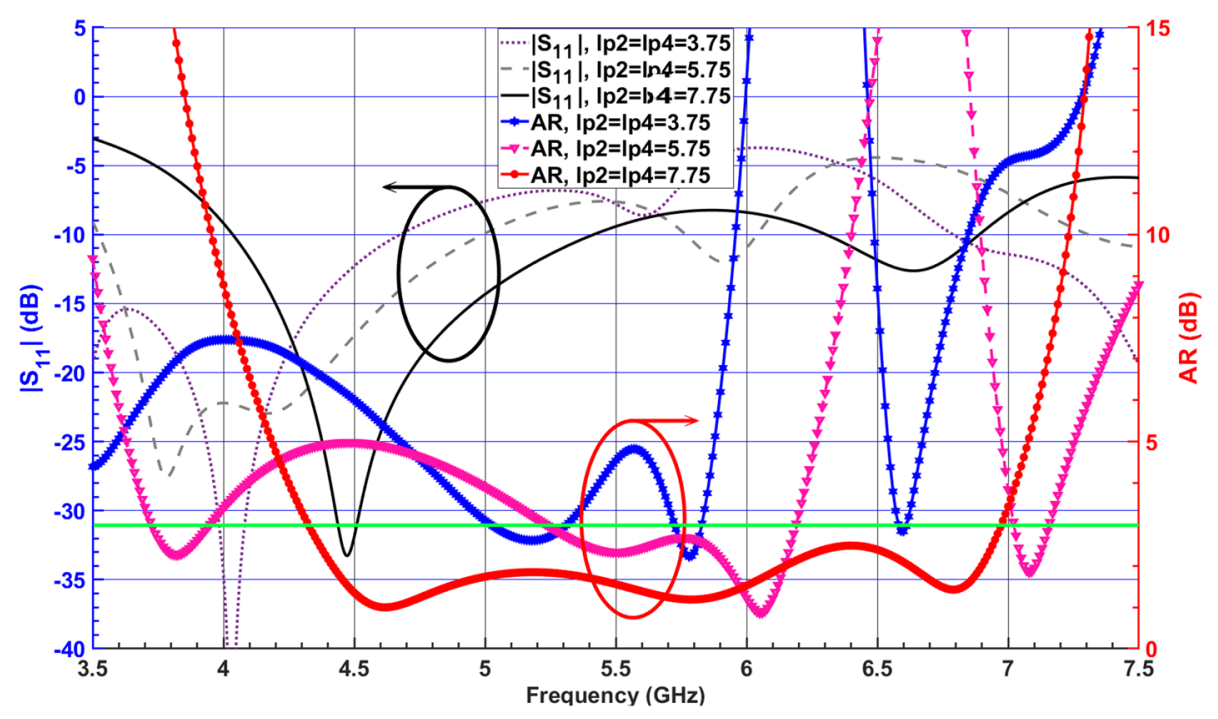

Figure 3. Simulated $\left|S_{11}\right|$ and ARs of the SDRA with different values of $l_{p 2}=l_{p 4}$.

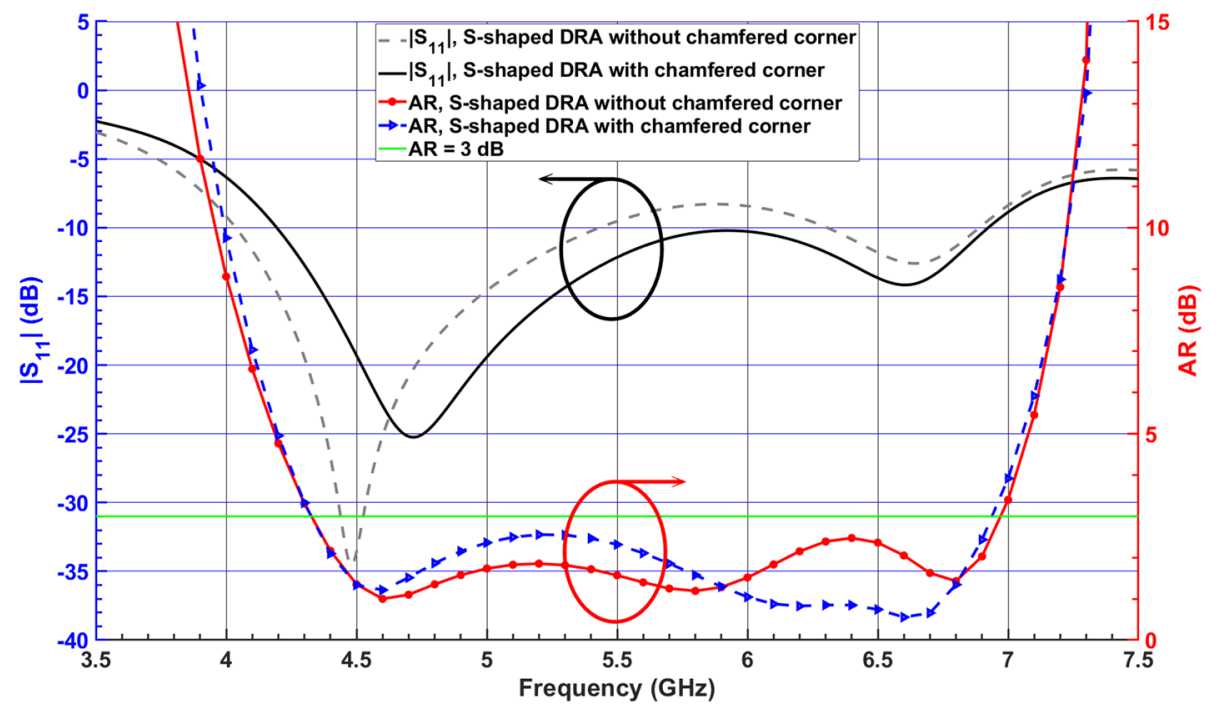

Figure 4. Simulated $\left|S_{11}\right|$ and ARs of the SDRA with and without chamfered corner.

that orthogonal modes with equal magnitude and quadrature-phase are excited at $4.6 \mathrm{GHz}$ and $6.5 \mathrm{GHz}$. It is worth mentioning that the resonant modes excited across the desired CP band resemble orthogonal $T E_{\delta 11}^{x}, T E_{1 \delta 1}^{y}$, $T E_{131}^{x}$, and $T E_{311}^{y}$ modes.

Radiation characteristic improvement and beam squint reduction. Figure 6 illustrates the simulated $\mathrm{H}$ - and E-plane radiation patterns at $6.5 \mathrm{GHz}$ for three different cases: Antenna I, Antenna II, and Antenna III, as shown in Fig. 1b-d, respectively. As for Antenna I, it is observed that the radiation pattern in the broadside direction deviates from the $+z$-direction with a high beam squinting of $-41^{\circ}$, which does not satisfy the required specifications for $\mathrm{CP}$ antennas.

To fix the beam squint effect at $6.5 \mathrm{GHz}$, a RDR is placed in front of the SDRA to concentrate radiative fields toward the boresight (see Fig. 1c). The RDR is excited by a small rectangular-shaped parasitic strip attached to the coaxial probe to improve the symmetry of the radiation patterns at the upper bands due to exciting higherorder modes inside the RDR. Another important parameter that has a significant effect on the AR and $\left|S_{11}\right|$ is $a_{2}$. Figure 7 illustrates the effect of varying $a_{2}$ on the AR and $\left|S_{11}\right|$, indicating that by increasing $a_{2}$, from 10 to $18 \mathrm{~mm}$, the higher edge of the bandwidth is increased. The separation between the corresponding resonant frequencies of the excited orthogonal modes inside the DRA increases the AR bandwidth. It is noticed that the beam squinting is reduced to $28^{\circ}$, which leads to an increased LHCP gain from $3.17 \mathrm{dBic}$ to $3.8 \mathrm{dBic}$ at $6.5 \mathrm{GHz}$. 


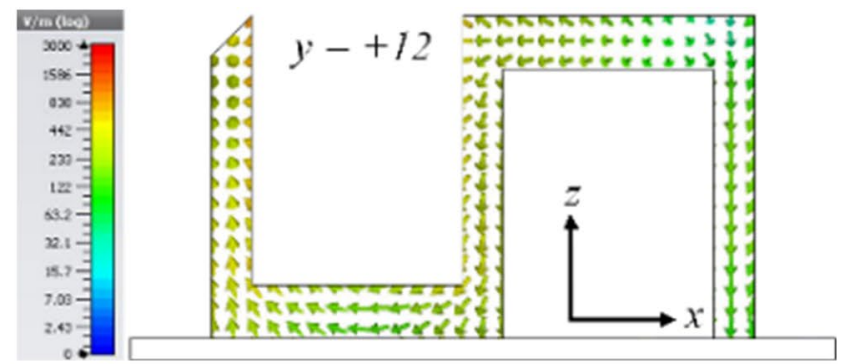

(a)

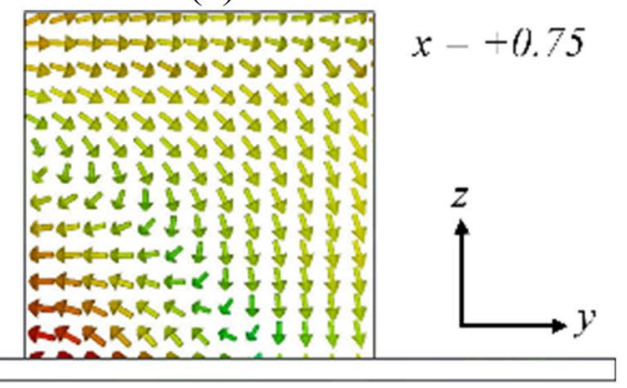

(c)

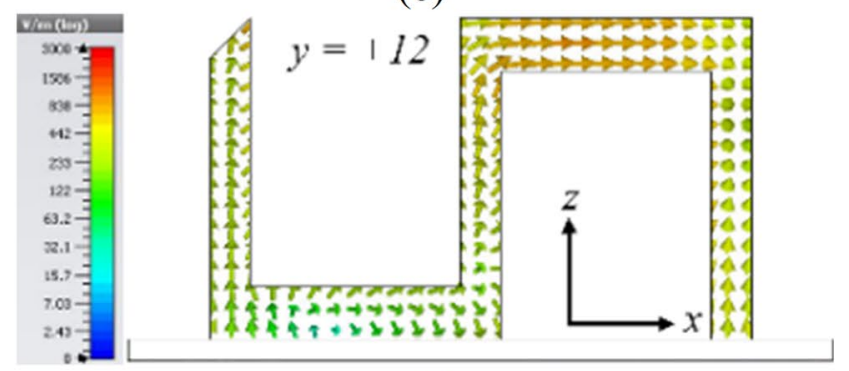

(e)

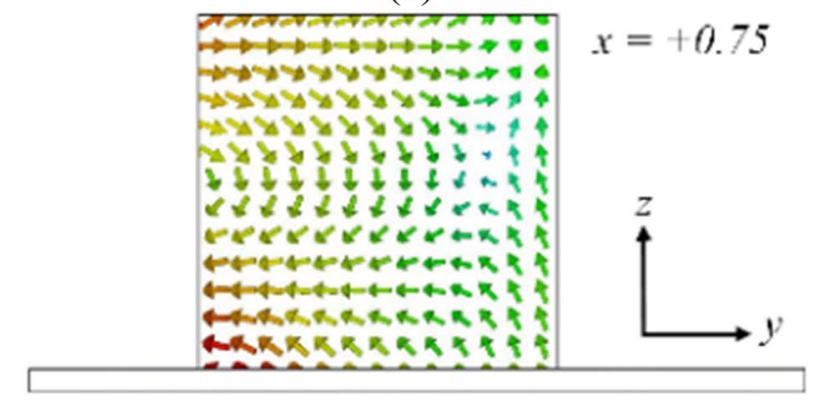

(g)

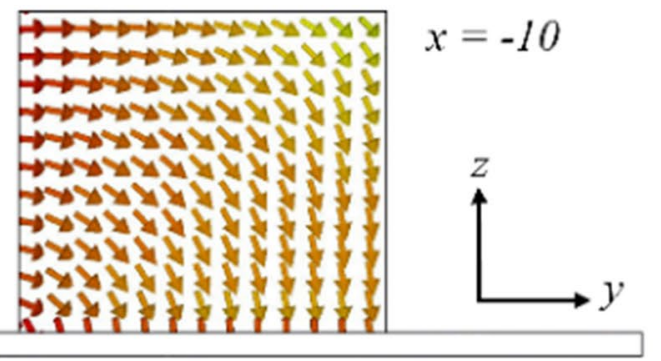

(b)

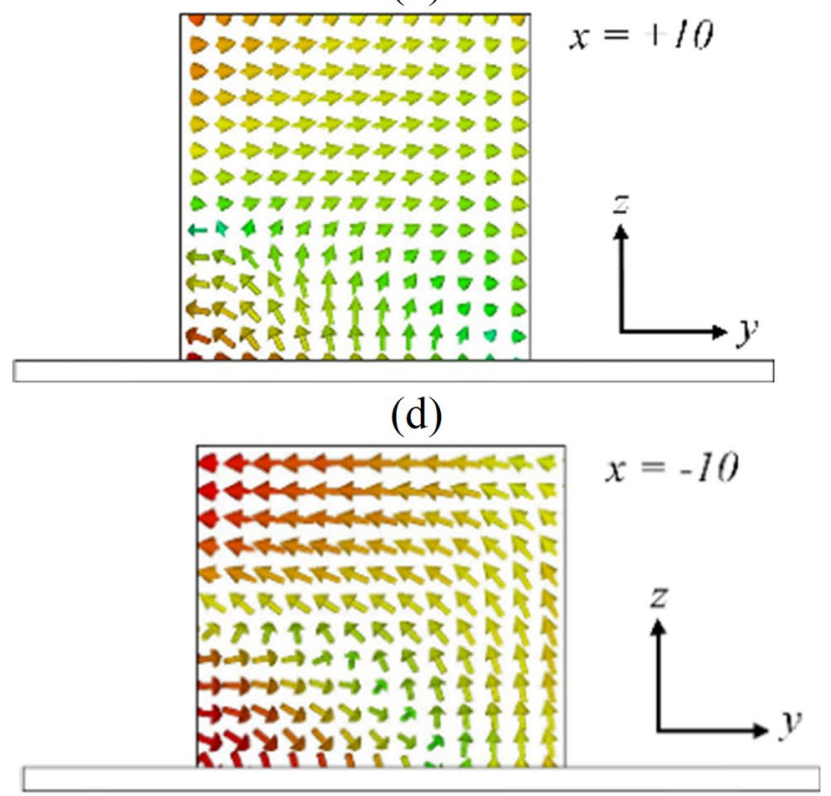

(f)

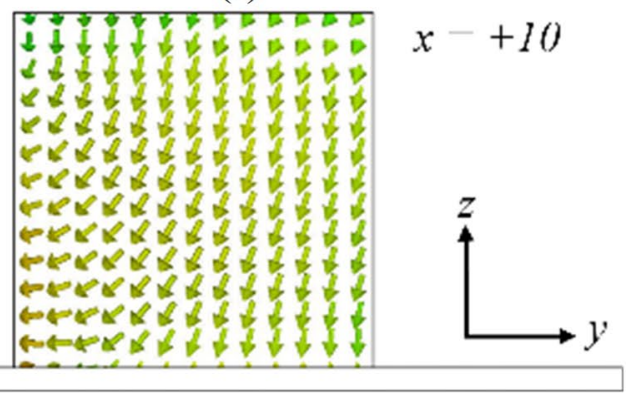

(h)

Figure 5. Simulated electric field vectors on different surfaces of the SDR; at $4.6 \mathrm{GHz}$ (a) $T E_{1 \delta 1^{\prime}}^{y} \measuredangle 45^{\circ}$ $(y=12 \mathrm{~mm}),(\mathbf{b}) T E_{\delta 11}^{x} \measuredangle 135^{\circ}(x=-10),(\mathbf{c}) T E_{\delta 11}^{x} \measuredangle 135^{\circ}(x=+0.75)$, and (d) $T E_{\delta 11}^{x} \measuredangle 135^{\circ}(x=+10)$; at 6.5 $\mathrm{GHz}(\mathbf{e}) T E_{311^{\prime}}^{y} \measuredangle 45^{\circ}(y=12 \mathrm{~mm}),(\mathbf{f}) T E_{131}^{x} \measuredangle 135^{\circ}(x=-10),(\mathbf{g}) T E_{131}^{x} \measuredangle 135^{\circ}(x=+0.75)$, and (h) $T E_{131}^{x} \measuredangle 135^{\circ}$ $(x=+10)$; (color bar shows the amplitude of the E-field.

A vertical metal strip is then placed on one side of the thin RDR slab at a distance of $l_{d}=2 \mathrm{~mm}$, as illustrated in Fig. 1c. By applying the vertical metal strip, the CP bandwidth and impedance matching are enhanced because of the increased effective resonator dimension in the $\mathrm{x}$-direction. This leads to a downward shift in the resonant frequency of the corresponding higher-order $\operatorname{modes}^{30}$, as shown in Fig. 8.

Finally, to further minimize the beam squint, the second RDR is horizontally attached to the aforementioned DR blocks in the y-direction, as shown in Fig. 1d. The second RDR effect with width $a_{3}$, on the antenna performance, is exhibited in Fig. 9. It is observed that the AR and $\left|S_{11}\right|$ are shifted down to the lower frequency as the width of the second RDR increases from 2 to $6 \mathrm{~mm}$. The widest overlapping bandwidth is achieved at $5.25 \mathrm{~mm}$. Referring to Fig. 6 , the boresight gain increases from $3.8 \mathrm{dBic}$ at $\theta=-28^{\circ}$ to $4.7 \mathrm{dBic}$ at $\theta=0^{\circ}$ for 6.5 $\mathrm{GHz}$ frequency. It is noted that by applying the horizontal $\mathrm{RDR}, T E_{121}^{z}$ mode is excited inside the SDR, which is orthogonal to the existing $T E_{112}^{y}$ mode excited within the first RDR, as shown in Fig. 10. Furthermore, by increasing the effective resonator dimension in the $y$-direction, the total ratio of dominant orthogonal modes 


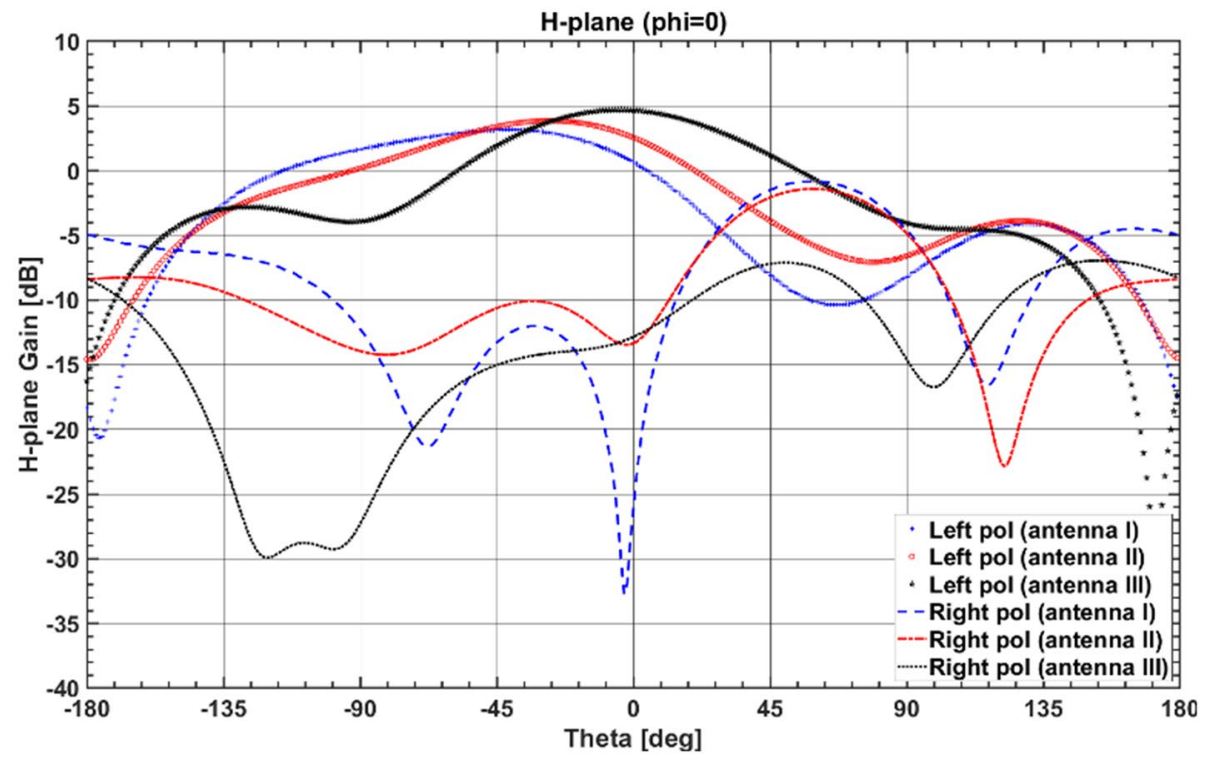

(a)

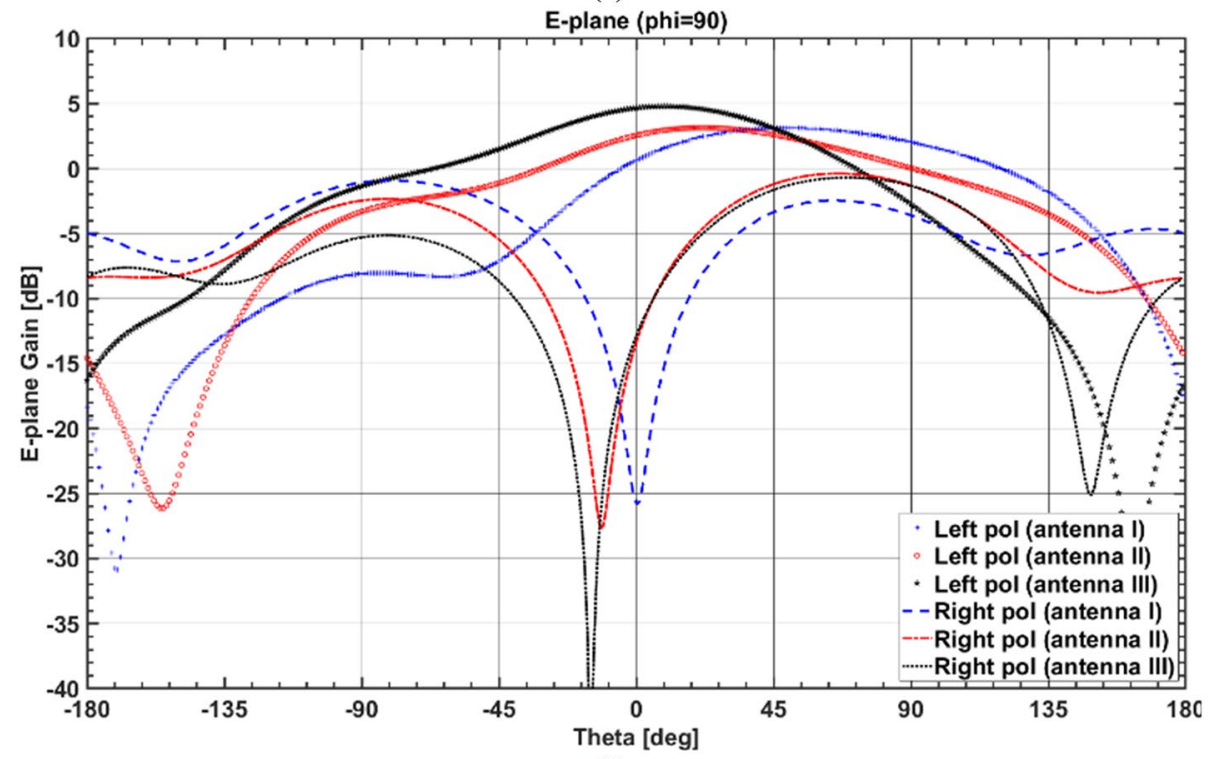

(b)

Figure 6. Simulated (a) H-plane and (b) E-plane radiation patterns of Antenna I, Antenna II, and Antenna III at $6.5 \mathrm{GHz}$.

inside the DRA can be improved. This results in pattern rotation towards $\theta=0^{\circ}$ and gain enhancement. Based on this phenomenon, the 3-dB AR and impedance bandwidths shift down to the lower band, resulting in a wider impedance bandwidth of about $66.9 \%(3.66-7.34 \mathrm{GHz})$ and 3-dB axial-ratio (AR) bandwidth of about 54.54\% $(3.76-6.58 \mathrm{GHz})$.

\section{Measured and simulated results}

In this work, to reduce the complexity of design and fabrication difficulty, two additional DR blocks are combined to form an L-shaped DR. Therefore, one S-shaped and L-shaped DR blocks are placed and fixed in the desired location to achieve satisfactory performance. In addition, a vertical metal strip is glued on a ROHACELL HF Foam $\left(\varepsilon_{r o}=1.04\right)$, and then the L-shaped DR and foam are assembled on top of the substrate using RTV silicone adhesive $\left(\varepsilon_{g} \approx 3\right)$ to construct the CP DRA with a vertical metal strip. There are various techniques to measure the axial ratio ${ }^{8,9}$. In the proposed work, the right-hand CP (RHCP) and left-hand CP (LHCP) patterns, and AR are measured using the method proposed in ${ }^{8}$. The dielectric resonator antenna radiation patterns are measured by rotating a linearly polarized horn antenna as a transmitter considering two planes $\phi=0^{\circ}$ and $90^{\circ}$. Meanwhile, the $\mathrm{AR}$ is defined using a spinning source antenna with linear polarization in the experimental setup, which requires the source horn to rotate around its $\mathrm{z}$-axis in the ( $\phi$-direction) while moving the antenna under test (AUT) in the azimuth direction. 


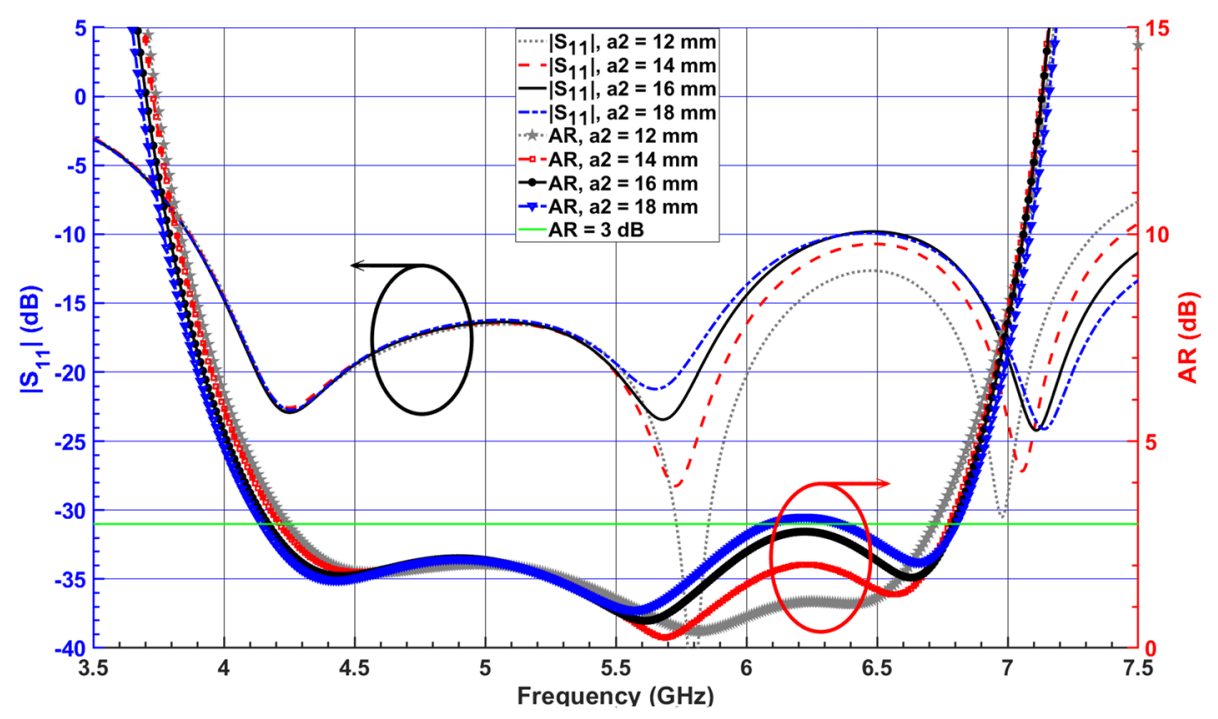

Figure 7. Simulated $\left|S_{11}\right|$ and ARs for the DRA (Antenna II) versus various total lengths $a_{2}$ of the first added $\mathrm{RD}$.

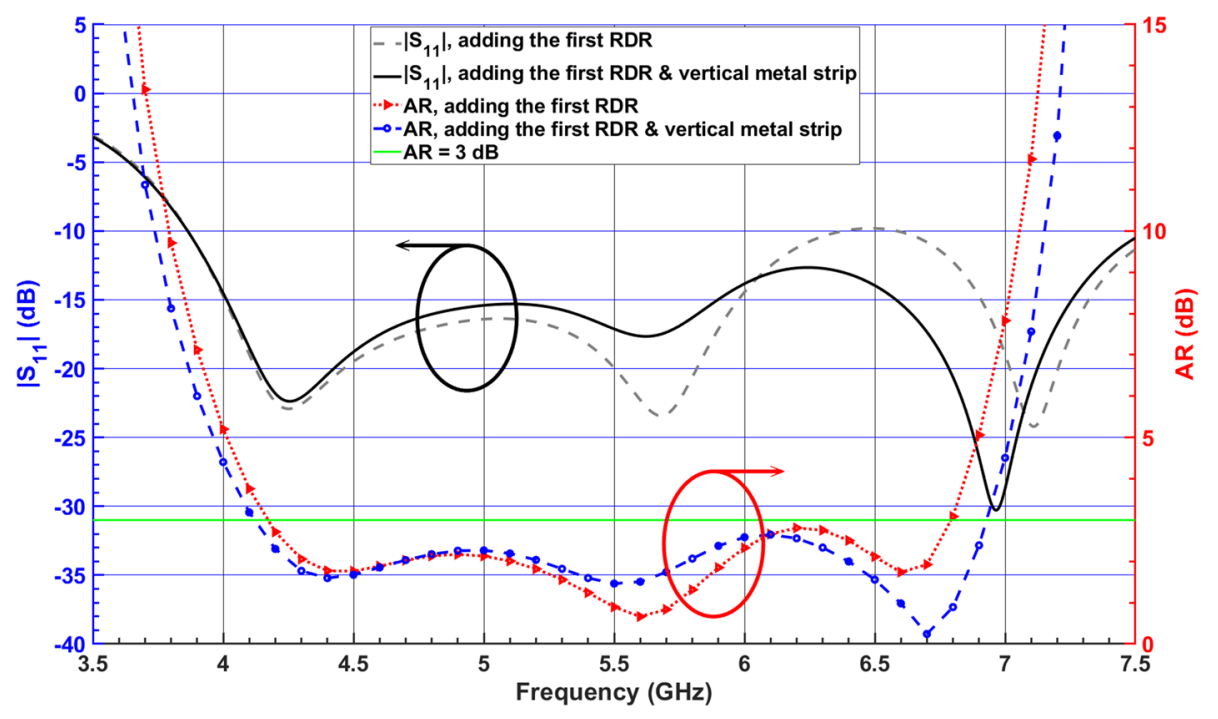

Figure 8. Simulated $\left|S_{11}\right|$ and ARs of the DRA (Antenna II), adding the first RDR block and vertical metal strip.

S-parameter and axial ratio measurement. The simulated and measured frequency response of 3-dB $\mathrm{AR}$ and $\left|S_{11}\right|$ of the proposed antenna is depicted in Fig. 11, representing a close agreement between the simulated and measured results. The CP-DRA provides an impedance bandwidth of about $66.8 \%(3.71-7.45 \mathrm{GHz})$ and a $3-\mathrm{dB}$ axial-ratio bandwidth of about $54.8 \%(3.72-6.53 \mathrm{GHz})$.

Far-field measurement. Figure 12 illustrates the simulated and measured radiation patterns of the proposed DRA in $x z$-plane $\left(\phi=0^{\circ}\right)$ and $y z$-plane $\left(\phi=90^{\circ}\right)$. It can be seen that the proposed DRA's radiation patterns remain stable within the desired operating band. It can be observed from the figure that the difference between LHCP and RHCP radiation levels is more than $18 \mathrm{~dB}$ confirming the purity of the LHCP radiation. Figure 13 shows simulated radiation efficiency along with the measured and simulated boresight gain of the proposed CP-DRA versus frequency. It is observed that a squint-free radiation pattern is obtained with a peak gain at boresight compensating the beam squint of $41^{\circ}$. The antenna efficiency remains at more than $97 \%$ throughout the passband of the DRA. Furthermore, the proposed antenna provides a gain of more than $2.85 \mathrm{dBic}$ within the desired 3-dB AR bandwidth with a peak gain of about $4.64 \mathrm{dBic}$.

Comparison with the state-of-the-art designs. Table 1 presents a comparison between the proposed CP-DRA and the previously reported designs, where $\lambda_{0}$ is the wavelength at the center frequency of the passband 


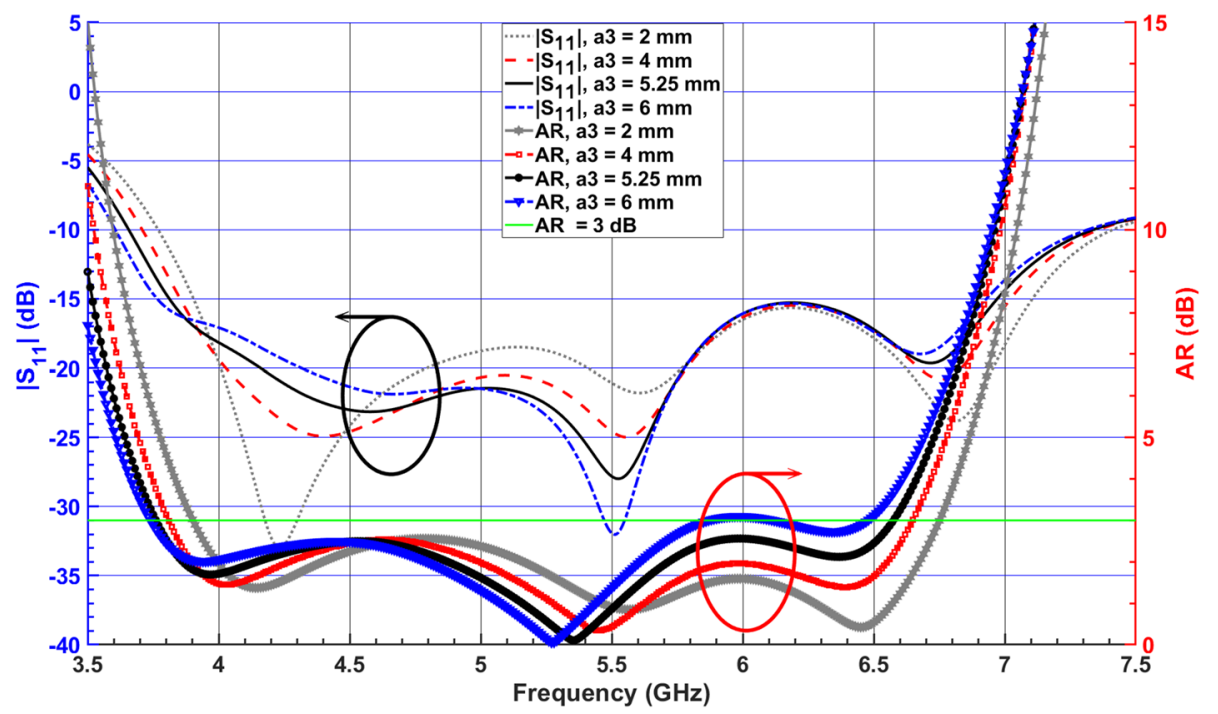

Figure 9. Simulated $\left|S_{11}\right|$ and ARs for the DRA (Antenna III) with various total widths $a_{3}$ of the second added RDR.

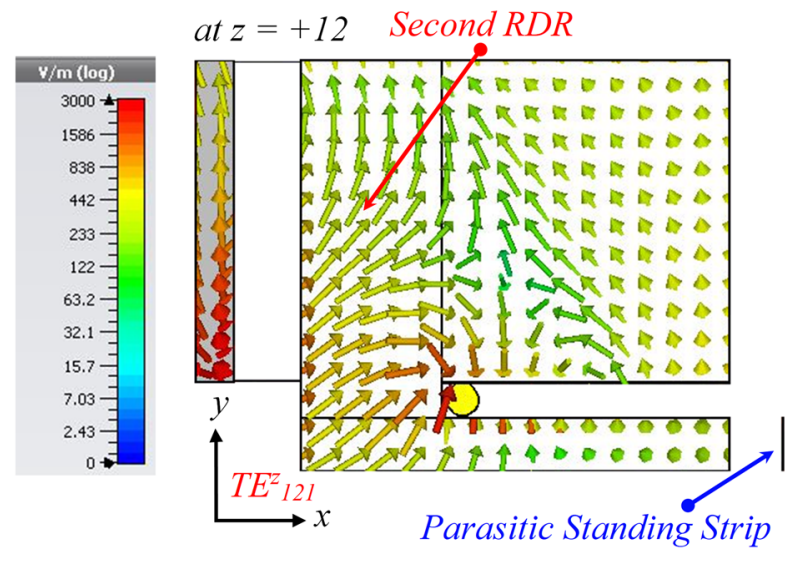

(a)

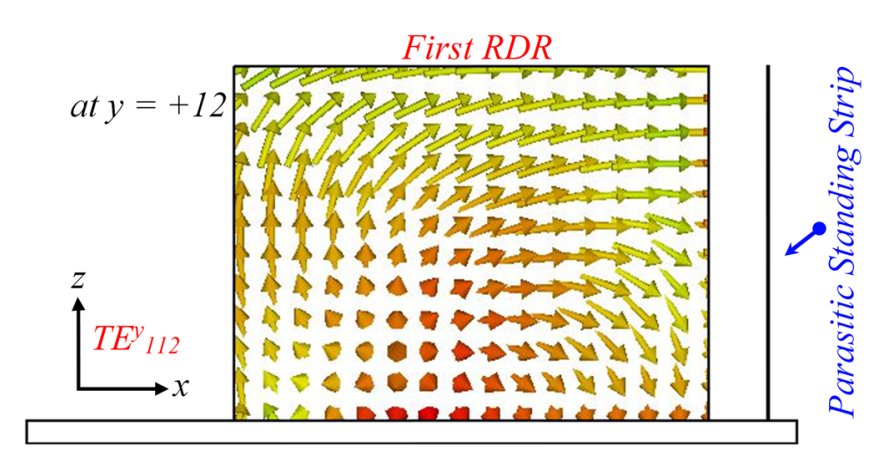

(b)

Figure 10. Simulated electric field vectors on the top surface of the SDR and the vertical surface of the first $\mathrm{RDR}$ at $5.5 \mathrm{GHz}$ (a) $x y$-plane $\left(T E_{121}^{z}\right) \measuredangle 0^{\circ}(z=12 \mathrm{~mm})$, (b) $x z$-plane $\left(T E_{112}^{y}\right) \measuredangle 90^{\circ}(y=12 \mathrm{~mm})$; (color bar shows the amplitude of the E-field).

in free space. Compared to the state-of-the-art techniques reported in the literature, the proposed antenna offers a relatively wider AR bandwidth with squint-free radiations and a competitive trade-off between compactness and CP bandwidth.

\section{Conclusion}

A novel wideband circularly polarized DRA with squint-free radiation characteristics has been proposed. The proposed CP-DRA consists of an S-shaped dielectric resonator block with one metalized edge connected to a coaxial probe, two horizontally and vertically loaded rectangular DRs, and a small metal strip attached to the vertical DR connected to the coaxial probe. Additionally, a vertical metal strip is placed parallel to the vertical DR's outer edge to achieve better antenna bandwidth. To enhance the CP bandwidth, the rectangular DR is modified to form an S-shaped DR by deducting two equal rectangular-shaped blocks from RDR. A 100\% correction of beam squinting $\left(\theta=41^{\circ}\right)$ with respect to boresight has been obtained by loading two horizontally and vertically positioned RDRs (L-shaped DR). The experimental results have demonstrated that the proposed CP-DRA achieved about $66.8 \%(3.71-7.4 \mathrm{GHz})$ of matching bandwidth, which completely covers the 3-dB AR of about $54.8 \%(3.72-6.53 \mathrm{GHz})$ demonstrating its potential for various applications, such as compact communications, satellite communications, 5G Wi-Fi, WLAN, and WAP. 


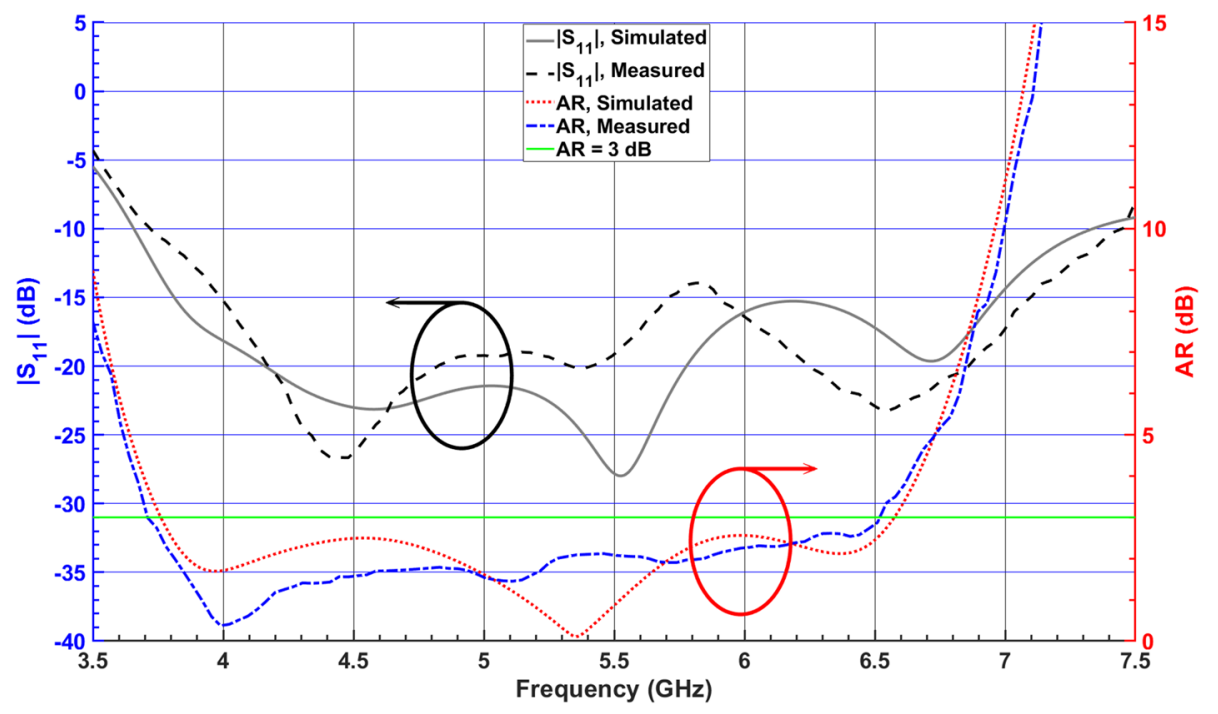

Figure 11. Simulated and measured $\left|S_{11}\right|$ and ARs of the proposed CP DRA.
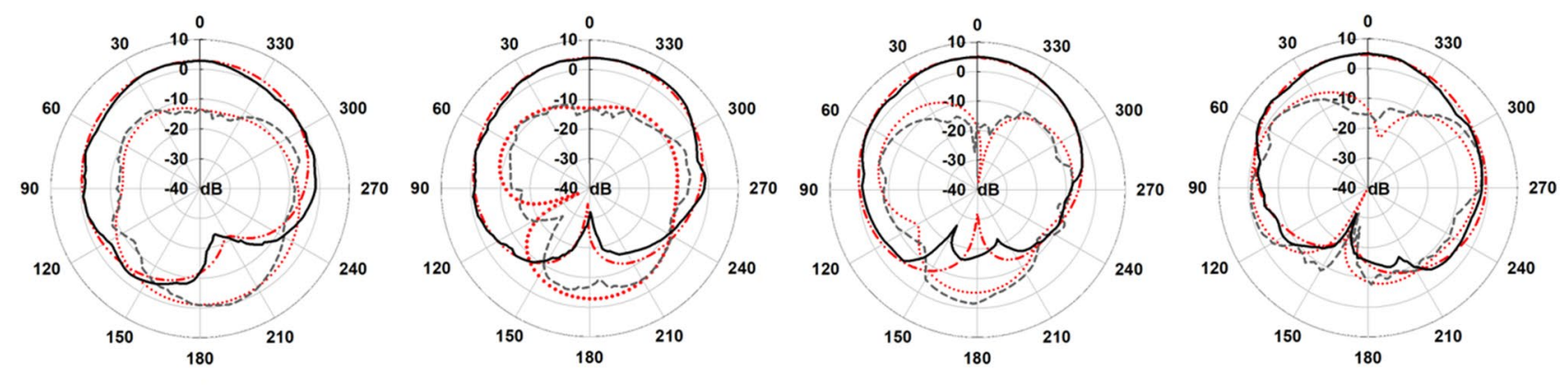

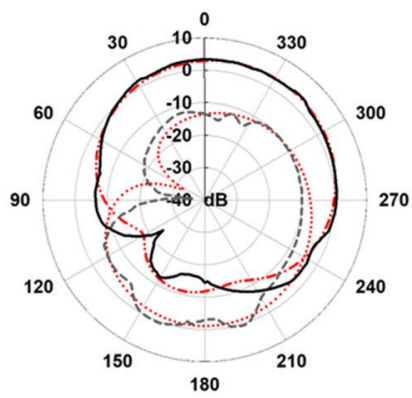

(a)

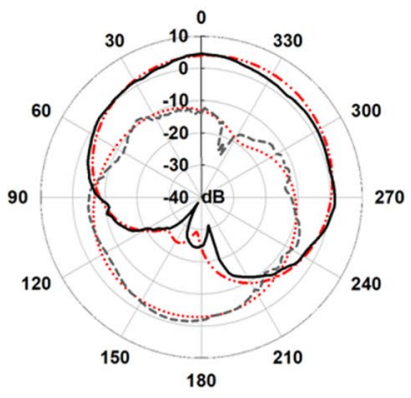

(b)

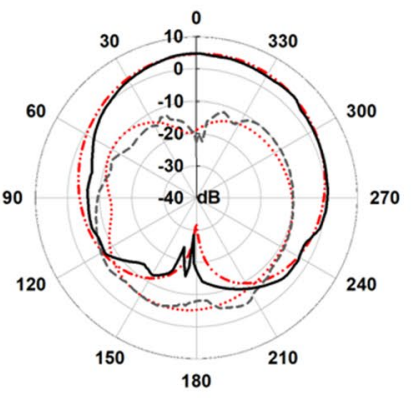

(c)

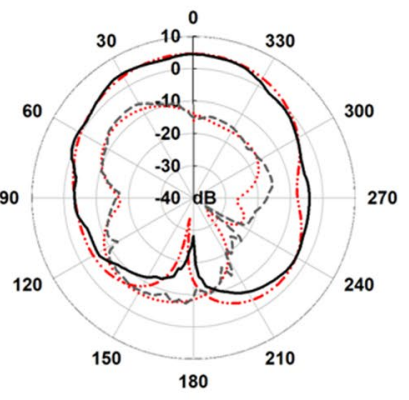

(d)

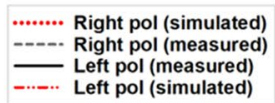

Figure 12. Simulated and measured LHCP and RHCP radiation patterns in $y z$-plane (up) and $x z$-plane (down) at (a) $3.76 \mathrm{GHz}$, (b) $4.6 \mathrm{GHz}$, (c) $5.5 \mathrm{GHz}$, and (d) $6.5 \mathrm{GHz}$. Red and black curves represent simulated and measured results, respectively. 


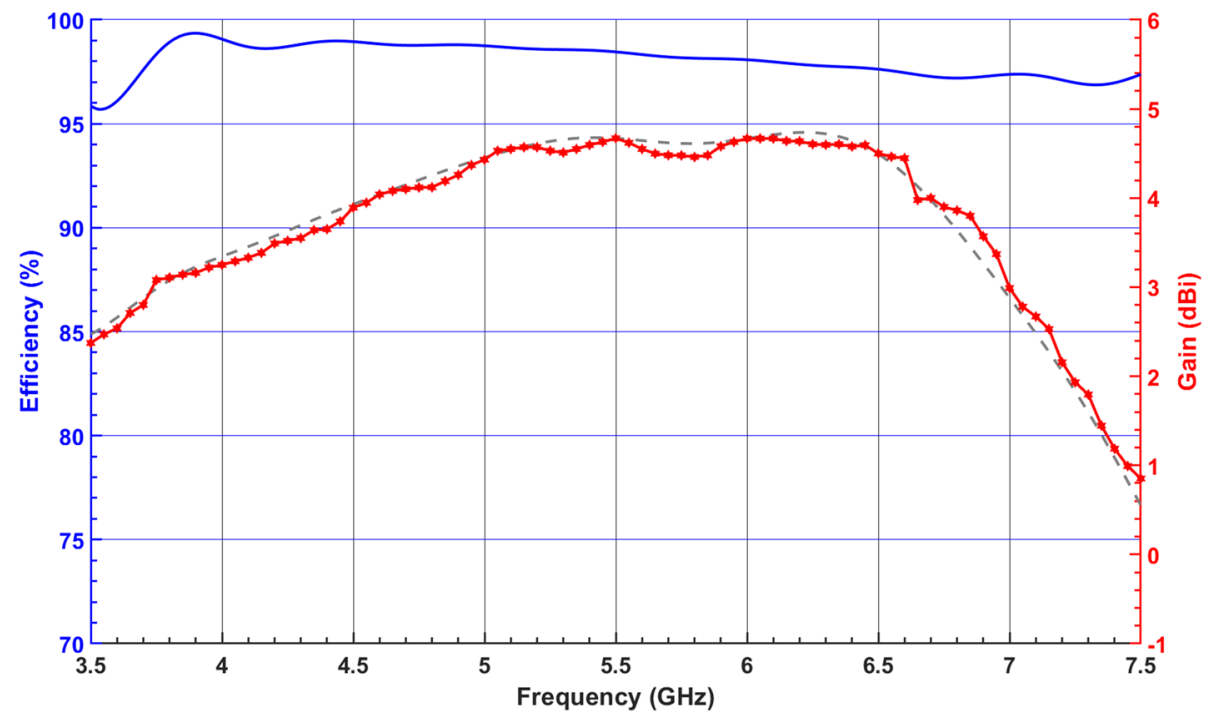

Figure 13. Measured and simulated boresight gain of the proposed CP-DRA and simulated radiation efficiency.

\begin{tabular}{|l|l|l|l|l|l|}
\hline Ref. & $\varepsilon_{r}$ & Antenna dimensions $\left(\lambda_{\mathbf{0}}^{\mathbf{3}}\right)$ & Imp. BW (\%) & AR BW (\%) & Peak gain $(\boldsymbol{d B i c})$ \\
\hline 15 & Anisotropic DR & $1.06 \times 1.06 \times 0.123$ & 33.5 & 26.3 & 8.5 \\
\hline 16 & 10 & $0.50 \times 0.44 \times 0.42$ & 69.66 & 44.73 & 6.34 \\
\hline 19 & 10 & $0.647 \times 0.647 \times 0.122$ & 50.8 & 36 & 6 \\
\hline 20 & 12 & $0.575 \times 0.575 \times 0.092$ & 30.4 & 25.5 & 4.95 \\
\hline 21 & 10 & $4.9 \times 4.9 \times 0.365$ & 27.7 & 20 & 6.8 \\
\hline 22 & 10 & $0.724 \times 0.724 \times 0.189$ & 46.9 & 46.9 & 4.73 \\
\hline 23 & 10 & $0.437 \times 0.437 \times 0.336$ & 59.8 & 20.8 & 4.91 \\
\hline 24 & 12.8 & $1.455 \times 1.455 \times 0.105$ & 49.7 & 41 & 1.5 \\
\hline 25 & 9.8 & $0.61 \times 0.61 \times 0.273$ & 30.4 & 24.6 & 5.5 \\
\hline This work & 10 & $0.484 \times 0.484 \times 0.237$ & 66.8 & 54.8 & 4.64 \\
\hline
\end{tabular}

Table 1. Comparison with CP DRAs in the literature.

Received: 8 December 2020; Accepted: 9 March 2021

Published online: 30 March 2021

\section{References}

1. Luk, K. M. \& Leung, K. W. (eds) Dielectric Resonator Antennas (Research Studies Press, 2003).

2. Leung, K. W., Lim, E. H. \& Fang, X. S. Dielectric resonator antennas: From the basic to the aesthetic. Proc. IEEE 100, 2181-2193 (2012).

3. Low, J. H. et al. Compact organic liquid dielectric resonator antenna for air pressure sensing using soft material. Sci. Rep. 10, 14907 (2020).

4. Nasimuddin, Chen ZN. \& Qing, x. Dual-band circularly polarized S-shaped slotted patch antenna with a small frequency-ratio. IEEE Trans. Antennas Propag. 58, 2112-2115 (2010).

5. Nasimuddin, Qing, X. \& Chen, Z. N. Microstrip antenna with S-shaped slot for dual-band circularly polarized operation. IEEE Eur. Microw. Conf. (EuMC) 381-384, (2009).

6. Petosa, A. \& Ittipiboon, A. Dielectric resonator antennas: A historical review and the current state of the art. IEEE Antennas Propag. Mag. 52, 91-116 (2010).

7. Kumar Mongia, R. \& Ittipiboon, A. Theoretical and experimental investigations on rectangular dielectric resonator antennas. IEEE Trans. Antennas Propag. 45, 1348-1356 (1997).

8. Toh, B. Y., Cahill, R. \& Fusco, V. F. Understanding and measuring circular polarization. IEEE Trans. Educ. 46, 313-318 (2003).

9. Li, B., Deng, Y., Zhang, J. \& Zhou, Z. Novel method for measuring the axial ratio of circularly polarized antennas based on the cross-polarization. Sixth Asia-Pacific Conf. Antennas Propag. (APCAP) 1-3, (2017).

10. Steven Yang, S. L., Ricky Chair, Kishk A. A., Lee, K. F. \& Luk, K. M. Study on sequential feeding networks for sub-arrays of circularly polarized elliptical dielectric resonator antenna. IEEE Trans. Antennas Propag. 55, 321-333 (2007).

11. Kaim, V. et al. Ultra-miniature circularly polarized CPW-fed implantable antenna design and its validation for biotelemetry applications. Sci. Rep. 10,6795 (2020).

12. Kishk, A. A. Elliptic dielectric resonator antenna for circular polarization with single feed. Microw. Opt. Technol. Lett. 37, 454-456 (2003).

13. Leung, K. W. \& Ng, H. K. Theory and experiment of circularly polarized dielectric resonator antenna with a parasitic patch. IEEE Trans. Antennas Propag. 51, 405-412 (2003). 
14. Chair, R., Kishk, A. A. \& Lee, K. F. Aperture fed wideband circularly polarized rectangular stair shaped dielectric resonator antenna. IEEE Trans. Antennas Propag. 54, 1350-1352 (2006).

15. Yang, M., Pan, Y., Sun, Y. \& Leung, K. Wideband circularly polarized substrate-integrated embedded dielectric resonator antenna for millimeter-wave applications. IEEE Trans. Antennas Propag. 68, 1145-1150 (2020).

16. Trinh-Van, S., Yang, Y., Lee, K. \& Hwang, K. C. Single-fed circularly polarized dielectric resonator antenna with an enhanced axial ratio bandwidth and enhanced gain. IEEE Access 8, 41045-41052 (2020).

17. Khoo, K. W., Guo, Y. X. \& Ong, L. C. Wideband circularly polarized dielectric resonator antenna. IEEE Trans. Antennas Propag. 55, 1929-1932 (2007).

18. Pan, Y. \& Leung, K. W. Wideband circularly polarized trapezoidal dielectric resonator antenna. IEEE Antennas Wirel. Propag. Lett. 9, 588-591 (2010).

19. Khalily, M., Kamarudin, M. R. \& Jamaluddin, M. H. A novel square dielectric resonator antenna with two unequal inclined slits for wideband circular polarization. IEEE Antennas Wirel. Propag. Lett. 12, 1256-1259 (2013).

20. Zou, M., Pan, J. \& Nie, Z. A wideband circularly polarized rectangular dielectric resonator antenna excited by an Archimedean spiral slot. IEEE Antennas Wirel. Propag. Lett. 14, 446-449 (2015).

21. Illahi, U. et al. Singly-fed rectangular dielectric resonator antenna with a wide circular polarization bandwidth and beamwidth for WiMAX/satellite applications. IEEE Access 7, 66206-66214 (2019).

22. Yang, M., Pan, Y. \& Yang, W. A singly fed wideband circularly polarized dielectric resonator antenna. IEEE Antennas Wirel. Propag. Lett. 17, 1515-1518 (2018).

23. Abedian, M., Rahim, S. K. A., Danesh, S., Jamaluddin, M. H. \& Islam, M. T. Compact wideband circularly polarised dielectric resonator antenna. Electron. Lett. 53, 5-6 (2017).

24. Varshney, G., Pandey, V. S., Yaduvanshi, R. S. \& Kumar, L. Wide band circularly polarized dielectric resonator antenna with stairshaped slot excitation. IEEE Trans. Antennas Propag. 65, 1380-1383 (2017).

25. Chowdhury, R., Mishra, N., Sani, M. M. \& Chaudhary, R. K. Analysis of a wideband circularly polarized cylindrical dielectric resonator antenna with broadside radiation coupled with simple microstrip feeding. IEEE Access 5, 19478-19485 (2017)

26. Kumar, B. P., Guha, D. \& Kumar, C. Reduction of beam squinting and cross-polarized fields in a wideband CP element. IEEE Antennas Wirel. Propag. Lett. 19, 418-422 (2020).

27. Kumar, R. \& Chaudhary, R. K. A wideband circularly polarized cubic dielectric resonator antenna excited with modified microstrip feed. IEEE Antennas Wirel. Propag. Lett. 15, 1285-1288 (2016).

28. Altaf, A., Yang, Y., Lee, K. \& Hwang, K. C. Circularly polarized spidron fractal dielectric resonator antenna. IEEE Antennas Wirel. Propag. Lett. 14, 1806-1809 (2015).

29. Sulaiman, M. I. \& Khamas, S. K. A singly fed wideband circularly polarized dielectric resonator antenna using concentric open half-loops. IEEE Antennas Wirel. Propag. Lett. 10, 1305-1308 (2011).

30. Rashidian, A., Shafai, L. \& Klymyshyn, D. M. Compact wideband multimode dielectric resonator antennas fed with parallel standing strips. IEEE Trans. Antennas Propag. 60, 5021-5031 (2012).

\section{Author contributions}

M.A. wrote the main manuscript text. All authors reviewed the manuscript.

\section{Competing interests}

The authors declare no competing interests.

\section{Additional information}

Correspondence and requests for materials should be addressed to M.A.

Reprints and permissions information is available at www.nature.com/reprints.

Publisher's note Springer Nature remains neutral with regard to jurisdictional claims in published maps and institutional affiliations.

(c) (i) Open Access This article is licensed under a Creative Commons Attribution 4.0 International License, which permits use, sharing, adaptation, distribution and reproduction in any medium or format, as long as you give appropriate credit to the original author (s) and the source, provide a link to the Creative Commons licence, and indicate if changes were made. The images or other third party material in this article are included in the article's Creative Commons licence, unless indicated otherwise in a credit line to the material. If material is not included in the article's Creative Commons licence and your intended use is not permitted by statutory regulation or exceeds the permitted use, you will need to obtain permission directly from the copyright holder. To view a copy of this licence, visit http://creativecommons.org/licenses/by/4.0/.

(C) The Author(s) 2021 